\title{
Engagement of Undergraduate Nursing Students in Virtual Learning Environment in Karachi Pakistan
}

\author{
Zohra Kurji $^{1}$, James M. Mwenda ${ }^{2}$, Amina Aijaz ${ }^{1}$ \\ Aga Khan University- School of Nursing and Midwifery Karachi, Pakistan ${ }^{1}$ \\ Aga Khan University- Advanced Nursing Studies (AKU-ANS), Nairobi, East Africa ${ }^{2}$
}

\begin{abstract}
Aga Khan University (AKU) is implementing blended learning $(B L)$ in their existing programs. This study reports the use of BL mode in one of the courses entitled Advanced Concepts of Community Health nursing (ACCHN), offered for undergraduate nursing students, for the first time in Karachi Pakistan. A qualitative exploratory design was adopted.The year II students of Post-RN BScN programme who were studying the course were invited to participate in the study. Data was collected by using focus group discussions (FGDs.). Students found ACCHN course flexible because of the use of blended modalities. They felt that their learning was enhanced by multiple resources shared by faculty on Moodle. In terms of strategies, students found Vodcasts useful. Moreover, few students felt DFs were not as useful, due to wordy posts, which were time consuming to read and understand. Students also found lack of facilitation by faculty on DFs. Students suggested that faculty can use synchronous modes such as Skype and Webex to summarize the discussions. Load shedding and low bandwidth were also discussed by students as obstacles in successful implementation of the course. The findings concluded that bandwidth and electricity issue at home needs to be resolved at the national level.
\end{abstract}

\section{Introduction}

World has become a global village. With changing world, new technologies have emerged out for many purposes. In education, this globalization has resulted in introduction of new pedagogies for teachings [1, 2]. Although, adapting to new pedagogies has always been challenging and tedious task that requires several efforts and time [2]; however, it brings innovation in the field of education and help students to engage in learning process [1]. In Blended learning (BL), there is a combination of the use of technological tools along with traditional face-to-face classroom instruction, which gives diverse flavour to the students [1, 2]. Two forms of BL exist: synchronous and asynchronous. In synchronous mode, virtual classroom environment is created and all students in a class access the same information in real time. Whereas asynchronous mode provides flexibility as learning takes place over an extended time period [1, 2]. Various institutions around the world have adopted blended learning mode of delivery in their graduate and undergraduate programmes. For example one study in Hong Kong identified different reasons to initiate BL programmes, which were: pedagogical richness, social interaction, personal agency, cost effectiveness and ease of revision [1]. Another study pointed out that BL mode has also been associated with better learning and attitude outcomes compared to the faceto-face mode [4]. In addition, several studies reported higher student satisfaction rates with the integration of technology in teaching and learning [2, 3, and 4]. It offers greater convenience to the students, more access towards knowledge and content; better time shifting between work and studies and easy communication with their peers [3,4]. Also, pace of learning is according to the level of student that give student a kind of satisfaction for their own learning and their self-confidence is raised [9]. Student having visual learning style supported this pedagogy while students' perceptions for using BL as a strategy for higher learning education vary with different learning styles [3].

Modern studies by the National Center for Education Statistics [5] and the Sloan Consortium [6] showed an increasing demand and reception of online learning. Other recent studies showed the expansion of blended learning [7]. Also, it has been argued that universities play a vital role in advancing their teaching and curricula; hence, they are looking for ways to develop new pedagogies and new teaching and learning modes in order to satisfy the actual and future needs of organizations and societies [8].

In terms of students' preference, BL mode of learning is becoming more and more preferable [9]. In the field of health care, it is expected from the students to get mastery over clinical reasoning skills; this requires knowledge, cognition, reflective inquiry and cognition [10]. To ingrain the skill of clinical reasoning in today's students who demand interactive learning, we need to simulate the engaged learning environment in a manner that provides a complex series of interactions with patients and other involved professionals [10, 11]. This gives an insight and reinforcement to educators teaching in the health professional field to introduce BL in their curricula as well. 
Despite all the advantages, there are some challenges that students face while integrating technology in higher education. One of the most important challenges is the pace at which new technology is emerging day by day, and keeping up with that pace is overwhelming [3,9]. No matter technology has replaced many learning tools, students expect to have teaching in classes as they think that is the most interactive way of learning [3]. Some other major problems students face with BL are: self-efficacy, time management, academic preparation and independent learning, while some may face problems in handling even simple web based technology $[9,12]$. Turkish University reported few unpleasant student experiences related to the use of technology such as teachers and instructional designers rarely used instructional software, or provided context where students could use technology for problem solving and communication [2].

Today as more and more institutions of higher education are said to be implementing blended learning approach in academic programmes, one of the private university in Karachi Pakistan, took a bold step to establish a university-wide Faculty Professional Development (FPD) Program for blended learning in 2011. The program aimed to build faculty capacity in BL and ensured that faculty members are abreast with current research and practice on blended learning [13]. Through the FPD several nursing faculty members were trained to use BL tools and technologies, and several courses have also been transformed from traditional face to face to BL mode. Nursing students have been exposed to blended learning approaches in some other nursing courses including Advance Concepts of Community Health Nursing (ACCHN).

\section{Aim of the study}

The aim of the study was to describe the experiences of the nursing students studying through Blended Learning mode in ACCHN course at a Private School of Nursing and Midwifery in Pakistan. In particular, findings from the study would help the course facilitators to become aware of the benefits and challenges of teaching ACCHN course via blended learning mode. This would further help them in improving content and teaching and assessment strategies in their blended learning courses in future.

\section{Methodology}

Following steps were used to transform the traditional course to BL mode.

Step 1: training of faculty via faculty development program from provost office
Step 2: built infrastructure by having Smart Class rooms, media room for recording lectures and provided hand held devices to the students.

Step 3: development of course site using Moodle as virtual learning environment (VLE) refer to Figure 1. Step 4: rearranging course objectives into module templates after approval of curriculum committee.

Step 5: permission process followed for copyright.

Step 6: upload modules to the Moodle after converting into exe file.

Step 7: after completion of the course students were asked to participate in the study.

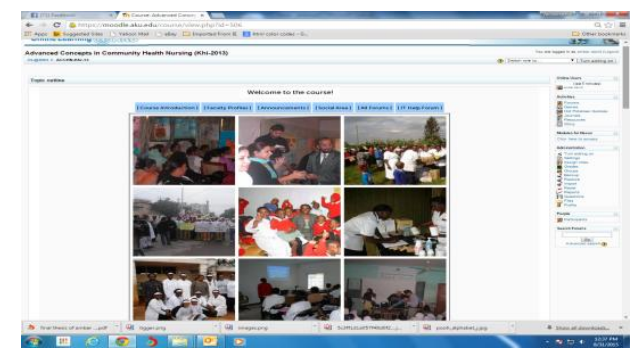

Figure 1. Development of course site using Moodle

A qualitative exploratory design was used to address the research question proposed for this study. The year II students of Post-RN BScN programme, who were studying the ACCHN course, were invited to participate in the study. Initially, four Focus Groups Discussions (FGDs) having eight students in each group were planned, however, because of saturation, we only conducted three FGDs. There were a total of 80 (72 female and 8 male) students enrolled in the course; out of 80 students, 24 were randomly selected by considering representation from both the genders. After taking clearance from University Ethical Review Committee, the students were selected based on their willingness to participate in the study after random selection. An informed consent was also taken from the research participants (students) before the study. The FGDs were conducted once the course was completed. The researchers conducted FGDs with the students to collect data on their experiences of studying ACCHN course via blended mode. These FGDs were tape recorded upon consent. Notes were also taken by researchers during FGDs. The data was manually analyzed and themes and categories were identified based on objectives of the study.

\section{Findings and discussion}

Three themes emerged from three FGDs which included: Organization's support on BL; useful blended learning tools including subcategories; vodcasts and podcast, Wiki, and discussion forums; 
and strength and challenges of BL and Students' recommendations.

\subsection{Theme 1: Organization's support on Blended Learning.}

Students in all three FGDs reported that they like the course site developed by the instructional designer and faculty. All of them appreciated the informational and technological support provided to them in asynchronous mode (such as discussion forum, developing posters, podcasts or vodcasts) as well as synchronous mode (Webx and Skype). They also acknowledged receiving handheld device (nook or nexus) from the university; however they were not fully satisfied with the quality of handheld devices provided to them. Students felt lost in first semester because of no knowledge on software and hardware. In addition, poor bandwidth and having no electricity for several hours is serious challenge which was faced by not only students but also by the educators.

While pointing out that students are the ultimate beneficiary of the success of blended learning approach, literature highlights concerns relating to students readiness to adopt the online technology, accessibility to the tools, and the ways that they will be assessed [1]. One more study observed that a basic requirement for e-learning is the access and availability of a stable Internet connection as well as computer [2, 3]. Similarly Bower, Dalgarno, Kennedy, Lee, \& Kenney have also mentioned the importance of appropriate handheld devices in their blended learning framework design [1,2, and 3]. At the University, we could resolve this challenge through an in built orientation program on blended learning for students, at the beginning of the academic program.

\subsection{Theme 2: Useful Blended Learning tools}

Several strategies were used in the ACCHN course such as wiki, digital storytelling, and discussion forums. Vodcasts and podcasts were not only uploaded by faculty but were developed by students on their assigned topics.

4.2.1. Category 1: Vodcasts and podcasts. In terms of strategies, students in this study found Podcasts and vodcasts as quite useful learning strategies to clarify the difficult concepts. Podcasts are multimedia files over internet for playback on mobile devices and personal computers. These are convenient tools for students to watch or to listen to on MP3 or iPods [14] and vodcasts or video podcasts are used for video broadcasting [14].

Literature suggests that the use of podcasts was significantly related to metacognitive listening and was strongly correlated with problem solving strategies, students' readiness and knowledge gained by students in English language course [16]. As Michael Zeiller noted blended learning scenarios using podcast benefited most students to compensate for the lack of face-to-face contact in distance learning phases. However, teachers need to understand that podcasting cannot be applied to all kinds of lectures [15], and can distract students if it's too long.

Literature mentions that it should not be assumed that all students have their personal computers and IPods [15]. In this group of students, institution was able to provide them with nook or nexus individually; this might be the reason that students liked this strategy the most.

5.2.2. Category 2: Wiki versus Google Doc. Wiki came out to be the least favourite strategy for collaborative work in our study, as students had to wait for their turns to work on the wiki because two students could not work simultaneously on the same wiki document. Some studies support that Wiki is not user friendly and identify same issue as a cause of frustration among students and state that when another student uses same page, that may result in a loss of work [17]; frustration may occur due to lengthy participation [18]; technical problems [16]; 'unproductive interactions' 'threats to privacy' [19]; and discomfort in the assessment process $[10,20]$. Morley argues that the successful employment of Wiki requires careful guidance by the teacher as to how the Wiki works, or it may be helpful with face to face teaching combination to support students' learning [16]. On the contrary some literature suggests that Wiki encourages critical thinking, selfreflection, flexible environment for collaborative learning, and is consistent with constructivist and Vygotskian theories of learning [20]. It also helps to organize students' learning, allows them to learn from each other [17, 18]. Google doc used later in this course seems to be an alternative and a more user friendly for students' collaborative learning.

5.2.3. Category 3: Discussion forum. In terms of discussion forums, few students felt that this was a good learning tool; however they felt lack of facilitation by faculty. In addition, students noted that discussion forums have plagiarism issues and wordy posts which were time consuming task for reading and commenting. Alebaikan and Troudi [21], identified E-plagiarism issues were common in discussion forums. They added that teachers may not recognize plagiarism due to high ratio of students per faculty. Further they reported that some teachers are aware of students' E-plagiarism and they send students warning notes of their plagiarism, but few teachers are not concerned and they felt that cut and paste is better than only providing reference for the material. Few authors give recommendation to 
enhance students' learning via discussion forums [21]. Alebaikan and Troudi also suggest importance of putting critical questions on discussion forums [21]. Smyth et al., suggest that in between all the blended pedagogies, small face to face sessions may benefit students to clarify concerns, consolidate learning and meet with peers to enhance consolidation of learning [22]. In our course we have now ten hours face to face workshop at the beginning of the course, as well as few face to face sessions in between the course.

\subsection{Theme 3: Strength and challenges of the BL}

In all three FDGs, students verbalized flexibility in using blended modalities offered in ACCHN course, as these helped them to balance the work, study, and family responsibilities. Students felt that their learning was enhanced by multiple resources shared by faculty. They verbalized that the modules were easy and feasible to follow and tasks given to them improved their litrature search skills for evidence based practice. Moreover, modules were helpful in enhancing student's critical thinking. Several studies support that blended learning is most flexible in regard to time and space and suits the needs of many adult learners; it can shift the traditionally rigid educational system, provided the teachers are trained, courses are appropriately designed and implemented for active participation, student engagement, and institutionally supported and their quality is maintained [14, 22, 23].

However, students faced several challenges in ACCHN course. In discussion forums several students did not follow netiquettes. Some students were threatened by the rubric for marking, which was part of the assessment for the discussion forums and was used for grading by faculty. Students felt some concepts were challenging like understanding frameworks. Students suggested that faculty should use more synchronous modes such as Skype and Webex to summarize the discussions or conduct session on difficult concepts. Moreover, they recommended that difficult concepts can also be done through physical presence of faculty in campus via face to face mode. Moreover, they felt that face to face learning will provide opportunity to meet with their class mates, which will help later on online discussion by being familiarized with each other. Students found challenging to work with larger group on discussion forum as there were some times 15-16 students. In addition, students experienced many challenges like lack of knowledge on soft and hardware, no electricity, and lack of internet connectivity. Literature also highlight students' challenges with blended learning programme such as social isolation and poor internet connectivity [27].

\subsection{Theme 4: Recommendations from participants}

Students felt that discussion forums should not be graded. Other assessment criteria like MCQs or other activities like poster developed by students should be utilized for grading. They advised reducing the number of discussion posts and limiting the word count posted by the students. They also recommended that facilitators should ask critical and meaningful questions to enhance critical thinking. Students recommended that an orientation with blended tools and technologies as well as ongoing support for them should be offered before the start of formal course work.

\section{Conclusion}

In conclusion, the findings reported in this study have led to significant modifications in ACCHN BL course including: reduction in the number of modules, introduction of in between face to face sessions to consolidate students' learning, as well as a limited number of discussion forums. Moreover, wiki has been replaced by other strategies like Google doc, vodcasts, podcast, C-map and digital story boarding. In terms of handheld devices, nook was replaced by nexuses which allowed students to contact facilitators in asynchronous mode. University has given High bandwidth to work in the university, however bandwidth and electricity issue at home needs to be resolved at the national level.

\section{Acknowledgments}

Noureen Asif Shivji former course faculty and Sahreen Chauhan Senior Research Coordinator, Blended and Digital Learning Network, Office of the Provost, Aga Khan University.

\section{References}

[1] N.G, Pin. and R. Ho-Leung Tsoi, "A Study on the Students" Perception of Adopting Blended Learning at Sub-degree Level". In F. Joseph, K. Reggie, W. Fu Lee, (Eds.): Hybrid Learning: A New Frontier, 2008, pp78-88. ICHL, City University of Hong Kong, Hong Kong, August 2008.

[2] Y. Akbulut. "Students' perception of change readiness of a Turkish Education Faculty regarding Information and Communication Technologies", Turkish Online Journal of Distance Education. 2009; 10(1):141-58.

[3] G. Banerjee, "Blneded Envionnment: Learning Effectiveness and Student Satisfaction at a small college in transition", Journal of Asynchronous Learning Networks, 2011; 15(1): 8-19.

[4] A. Uzun, and A. Senturk, "Blending Makes the Difference: Comparison of Blended and Traditional Instruction on Students' Performance and Attitudes in Computer Literacy", Contemporary Educational Technology, 2010; 1(3):196-207. 
[5] T. Waits, L, Lewis, Distance education at degree-granting postsecondary institutions: 2000-2001 (NCES 2003-017). US Department of Education, National Center for Education Statistics.

[6] I. E. Allen, and J. Seaman, Staying the course: Online education in the United States. Sloan Center for Online Education. December, 2008.

[7] Eynon, R.(2008). The use of the World Wide Web in learning and teaching in higher education: Reality and rhetoric. Innovations in Education and Teaching International.

[8] G. Filliona, M. Limayemb, T. Laferrièrec, and R. Manthac, "Integrating information and communication technologies into higher education: investigating onsite and online students' points of view", Open Learning, 2009; 24(3): 223-40.

[9] N. Vaughan, "Perspectives on Blended Learning in Higher Education", International Journal on E-Learning, 2007; 6(1): 8194.

[10]. S. Snodgrass, "Wiki activities in blended learning for health professional students: Enhancing critical thinking and clinical reasoning skills", Australasian Journal of Educational Technology, 2011; 27(4): 563-80

[11] G. J. Gormley, K. Collins, M. Boohan, I. Bickle, and M. Stevenson, "Is there a place for e-learning in clinical skills? A survey of undergraduate medical students' experiences and attitudes”, Medical Teacher, 2009; 31: e6-e12.

[12] G. Sheehy, "The wiki as knowledge repository: Using a wiki in a community of practice to strengthen K-12 education. TechTrends Internet, 2008; 52(6): 55-60.

[13] A. Naseem, Draft concept paper on University-wide Faculty Development Programme for Blended Learning. Karachi, Pakistan: Aga Khan University (AKU), 2012.

[14] M. Bower, B. Dalgarno, G. E. Kennedy, M. G. Lee, and J. Kenney, "Design and implementation factors in blended synchronous learning environments: Outcomes from a cross-case analysis", Computers \& Education, 2015; 86: 1-5

[15] M. Rahimi, and M. Katal, "The role of metacognitive listening strategies awareness and podcast-use readiness in using podcasting for learning English as a foreign language", Computers in Human Behavior, 2012; 28(4): 1153-1161.

[16] M. Zeiller, "Podcasting-based Mobile Learning in Blended Learning Courses". In Proceedings of ICL conference 2009, September 23-25, Page 518. Villach, Austria. Accessed 24/8/2015 http://www.icl-conference.org/dl/proceedings/2009/program/ pdf/Contribution_061.pdf

[17] P. Duffy, and A. Bruns, The use of blogs, wikis and RSS in education: a conversation of possibilities Proceedings Online Learning and Teaching Conference, Brisbane, 26 Sep, 2006; 31 38

[18] P. Colin, and L. Sanders, "An online collaborative document creation exercise in an ODL research project module", Computers \& Education, August 2014; 77, 116-124.

[19] G. Kurubacak, and T.V. Yuzer, Handbook of research on transformative online education and liberation: models for social equality. Hershey PA: Information Science Reference IGI Global, 2011.

[20] Carr, T., et al., (2007) 'Weathering wikis: net-based learning meets political science in a South African University', Computers and Composition, vol. 24, no. 3, pp. 266-284.
[21] R. Alebaikan, and S. Troudi, "Online discussion in blended courses at Saudi Universities", Procedia - Social and Behavioral Sciences, 2010; 2(2): 507-514.

[22] S. Smyth, C. Houghton, A. Cooney, and D. Casey, "Students' experiences of Blended learning across a range of postgraduate programmes", Nurse Education Today, 2012; 32(4): 464-468.

[23] M. Georgsen, C.V. Løvstad, "Use of Blended Learning in Workplace Learning”, Behavioral Sciences, 2014; 142: 774-780. 